Trinity University

Digital Commons @ Trinity

Communication Faculty Research

Communication Department

$12-2012$

\title{
Media Use and Postmaterialist Values in China and the US: A Comparative Study
}

Zhaoxi Liu

TrinityUniversity, zliu@trinity.edu

Follow this and additional works at: https://digitalcommons.trinity.edu/comm_faculty

Part of the Communication Commons

\section{Repository Citation}

Liu, Z. (2012). Media use and postmaterialist values in China and the US: A comparative study. Chinese Journal of Communication, 5(4), 383-398. doi:10.1080/17544750.2012.723384

This Post-Print is brought to you for free and open access by the Communication Department at Digital Commons @ Trinity. It has been accepted for inclusion in Communication Faculty Research by an authorized administrator of Digital Commons @ Trinity. For more information, please contact jcostanz@trinity.edu. 


\title{
Media use and postmaterialist values in China and the US: a comparative study
}

\author{
Zhaoxi Josie Liu*
}

School of Journalism and Mass Communication, The University of Iowa, Iowa City, USA

\begin{abstract}
This study uses data from the 2005 wave of World Values Survey (WVS 2005), to explore and compare the relations between media use and postmaterialist value orientations in China and the US. The data analysis showed that the younger generations in China have stronger postmaterialist value orientations than the older generations. American society has stronger postmaterialist value orientations than Chinese society as a whole, but fewer obvious generational differences. The study also found that media use has a greater effect on values in China than in the US.
\end{abstract}

Keywords: public opinion; international; comparative; postmaterialism; media use

The dramatic social transition now occurring in China has attracted academic attention from across disciplines, including political science (e.g., Tang, 2000, 2005) and mass communication (e.g., Lee, 2003; Zhao, 1998, 2008). A prominent topic in political science research is the change in values against the backdrop of social change (e.g., Inglehart, 1990, 1997, 2000, 2008; Inglehart, Basáñez, \& Menéndez Moreno, 1998; Welzel, 2008) although the case of China is not singled out. In the field of mass communications, much attention has been paid to changes in the press system, the transformation of media institutions, and the political and cultural implications for Chinese society (e.g., Brady, 2008; Lee, 2003; Zhao, 1998, 2008). However, fewer studies have made a connection between value change and media use in China (Yao, 2008; Zhu \& He, 2002) or compared China with other countries in this regard.

This study intends to fill the void in research by making an empirical connection between changes in values and the use of media in China and attempts to compare China with the US. It is important to make this connection because information is crucial for the formation, reinforcement, and change of human values, and in a modern society, media are a major source of people's information. China and the US provide two cases for a meaningful comparison because they are relevant to Inglehart's theory of economic security and value change (e.g., Abramson \& Inglehart, 1994; Inglehart, 1981; Inglehart \& Abramson, 1994). The US has been the largest economy in the world for decades, and its people have by and large attained relative economic security. China, on the other hand, is an example of a traditional society undergoing fast modernization and industrialization that in recent decades has just started to experience significant economic growth and affluence. The comparison between China and the US therefore can further shed light on the relation 
between economic development and postmaterialism. Using the US, a typical western developed country, as a reference for China's development can also help to further the understanding China (Cheng \& Schweitzer, 1996), a country where research on postmaterialism is urgently needed.

Through a series of statistical analyses of data from the 2005 wave of World Values Survey (WVS 2005), ${ }^{1}$ this study explores and compares the relations between media use and postmaterialist value orientations in China and the US. After the hypotheses and the research question are presented, the methods used in this study are discussed, followed by a discussion of the results of the statistical data analysis.

\section{Literature review}

\section{Value systems and changes}

Values are enduring beliefs that guide and determine people's actions, attitudes, ideology, and views of themselves, others, and the world (Rokeach, 1973). As important as they are, their measurement poses a great challenge to researchers. Nonetheless, many scholars have explored ways to measure values, and three of them are widely cited - Milton Rokeach, Shalom Schwartz, and Ronald Inglehart.

Rokeach (1973, p. 5) held that "a value is an enduring belief that a specific mode of conduct or end-state of existence is personally or socially preferable to an opposite or converse mode of conduct or end-state of existence". He therefore differentiated two kinds of values: (1) instrumental values or means-values, which concern desirable modes of conduct; and (2) terminal values, or ends-values, which concern desirable end-states of existence. Rokeach and his colleagues developed a research project called Value Survey to measure 18 terminal plus 18 instrumental values (Rokeach, 1973).

Schwartz's (1994) research on the basic content and structure of human values focused on the motivational goals lying behind values. His value system contains ten items, which according to him are shared by all human societies: power (authority, wealth), achievement (being successful), hedonism (pleasure, enjoying life), stimulation (daring, exciting life), self-direction (creativity, curious freedom), universalism (equality, social justice), benevolence (honest, helpful), tradition (humble, devout), conformity (politeness), and security (national security, social order) (Schwartz, 1994, p. 22).

Inglehart et al. developed a theory of value change to address mainly the shift from materialist to postmaterialist values in advanced industrial or postindustrial societies, which is the theory used in the current study. Inglehart based his theory on two hypotheses: scarcity and socialization (Inglehart, 2008; Inglehart et al., 1998). The scarcity hypothesis postulates that people will give priority to what they need most, but it is in short supply. In other words, people's socioeconomic conditions greatly influence their value orientations. Based on this hypothesis, people's living conditions, particularly in terms of material supply, influence their value priorities. The value priorities of people who grow up struggling to have enough food, clothing, and shelter tend to be placed upon material sustenance and physical security. The priorities of people who grow up taking survival for granted are likely to be other goals, such as feeling belonged, political freedom, and self-expression (Inglehart, 2008; Inglehart et al., 1998; Welzel, 2008). Materialist values, therefore, reflect people's lower-ordered needs or physiological survival needs whereas postmaterialist values reflect people's higher-ordered, psychological self-actualization needs (Welzel, 2008). 
The socialization hypothesis states that people's values are shaped during the formative years before they reach adulthood. The living conditions prevailing during one's pre-adult years determine value priorities, which are not very likely to change much as the person ages (Abramson \& Inglehart, 1994; Inglehart, 1981; Inglehart \& Abramson, 1994). It follows that value shifts in a society do not occur overnight but take place gradually as younger generations replace older ones to become the dominant population in a society. Inglehart stressed that value differences among different age groups reflect the effects of birth cohort, rather than the effects of life-circle. His research has shown that in developed societies, younger generations steadily demonstrate stronger postmaterialist value orientations than older generations. He also found that value orientations tend to remain consistent throughout a person's life span, that is, people do not show increased materialist value orientations as they age (Inglehart, 1990, 2008; Inglehart et al., 1998).

Therefore, for value change to occur there should be some obvious development in social economic conditions in a society as a whole. At the same time, value change does not take place in a decisive, across-the-board manner, but is more likely to appear in the form of intergenerational differences (Welzel, 2008). Based on the previous discussion of generational value change as a reflection and partly a result of changes in social economic conditions, the current study hypothesizes the following:

H1: Younger generations have stronger postmaterialist value orientations than older generations in China.

Inglehart and associates have maintained that economic security during the preadult years contributes to stronger postmaterialist value orientations. Social class, which relates to economic security, is also relevant to value orientations. They also analyzed empirical data to show that societies that have experienced rapid economic growth tend to have larger intergenerational differences (Abramson \& Inglehart, 1994; Inglehart \& Abramson, 1994). China seems to be a case in point.

In the past three decades, Chinese society has experienced dramatic changes in terms of economic and social development (Harding, 1987; Hutchings, 2001). Chinese people who reached adulthood before the Cultural Revolution experienced wars, famine, and political turmoil, while people growing up in the post-Mao reform era are likely to have no memories of extreme poverty or lasting social chaos. The US has been the largest economy in the world for decades, and its economic growth has been slow but stable in recent years. In the past 30 years, China has experienced more dramatic economic growth and social change than advanced industrial countries like the US. To compare value orientations in China and the US, this study tests two more hypotheses:

H2: American society has stronger postmaterialist value orientations than Chinese society as a whole.

H3: The generational differences of value orientations are more significant in China than in the US.

\section{Media use and values}

Many researchers have noticed that the connection between values and people's use of media is based on at least two factors. First, human values are derived, learned, and internalized in the context of society and its institutions, both cumulatively and over 
time (Rokeach, 1973). News media are one of society's key institutions, and therefore part of the forces that influence human values (Besley, 2008). Second, information is indispensable for the formation, maintenance, and change of values (Ball-Rokeach, Rokeach, \& Grube, 1984). Values are cognitive representations of societal demands, the need for a sense of mastery, and morality - ideas and judgments about rightnesswrongness. Values therefore serve primarily the maintenance and enhancement of self-esteem, which is a basic human need. Driven by this need, people pay attention to information that helps form evaluations of their competence or morality, and some of this information is obtained from the media (Ball-Rokeash et al., 1984).

Empirical studies have supported the proposition that media use impacts human values. Several studies show that watching television has the effect of stabilizing and reinforcing conventional capitalist values, such as materialism and consumerism (Besley, 2008; Carlson, 1993; Harmon, 2001). Using the European Social Survey (ESS), Besley (2008), for example, found a positive relationship between television watching, particularly entertainment programming, and two traditional capitalist values: conservation and self-enhancement. The results indicate that the dominant narrative provided by consumer-oriented programming reinforces existing power structures (conservation values) while also emphasizing the role of the individual as a consumer, "whose primary goals should be obtaining prestige and personal success as defined by existing social standards" (self-enhancement) (Besley, 2008, p. 14).

Another example is Reimer and Rosengren's (1990) study on the media's influence on value orientations in Sweden. They found that news consumption, whether of TV or newspapers, has strong correlations with both materialist and postmaterialist values. Watching entertainment on television is positively related to materialist values, while watching and reading about high culture - non-entertainment content, either TV or newspapers - has a strong positive correlation with postmaterialist values. The researcher took these as evidence that media use makes an independent contribution to the cultivation of those values.

In the case of the People's Republic of China (PRC), many scholars have pointed out the ruling communist party's deliberate use of propaganda for cultivating certain values. During the Mao era, for example, mass media were an important tool of ideological indoctrination aimed at changing people's attitudes and beliefs and cultivating a new value system based on socialism. Mao Zedong himself held the belief that people had to be taught, partly by mass media, to change the old values and beliefs inherited from pre-revolution China before they could behave like a citizen of a socialist country (e.g., Chu \& Hsu, 1979; Schurman, 1968). Mass media were also widely used during the early years of the PRC to form a common recognition of the new nation (Liu, 1971). Since the reform era, more and more foreign media products have entered China, providing the Chinese people with information on different life styles and values. Domestic media also started to diversify, challenging the dominance of the party's ideological propaganda (e.g., Lull, 1991; Lynch, 1999; Zha, 1995). The fast spread of Internet use in China has further contributed to the diversity of opinions and values among Chinese people, providing the forum for a variety of groups - dissidents, human rights activists, nationalists, supporters of democratic reforms as well as one-party rule, to name just a few - to express themselves. The government and the party's propaganda bodies are also among the avid users of the Internet (Tai, 2006; Zheng, 2007; Zhou, 2005). Still, the party tries to use mass media 
to foster values helpful for maintaining its rule, such as popular nationalism (e.g., Brady, 2008; Lee, 2003; Yu, 2009; Zhao, 2008).

Under such circumstances, it has become intriguing to explore the relations between media use and values in China, but not many empirical studies have been conducted in this area. In a survey of television viewing and endorsement of traditional Chinese values among Chinese college students, for instance, Zhang and Harwood (2002) found that the more time the respondents spent watching imported television, the less likely they were to endorse values of interpersonal harmony, a key element in traditional Chinese values. They related this finding to the fact that themes of individual achievement and success, hedonism, consumerism, and material comfort were prevalent in western television. Meanwhile, they found that viewing Chinese sports was a positive predictor of endorsing the value of hierarchical relations, another typical traditional Chinese value, because Chinese sports programs emphasize collective success and achievement, instead of individual athletes.

In short, many studies have found evidence indicating that media use affects values, whether in western countries or China. At the same time, it also should be pointed out that the relationship between media use and values tends to be complex. For example, Yao (2008) found that the statistically significant relationship between Chinese people's news media use and their environmental concern disappeared when political interests are controlled. Zhu and He (2002) also found that, although Internet users in Beijing and Guangzhou were more significantly likely to subscribe to postmaterialism compared with materialism and communism, little impact of Internet use on value choice was found when demographical variables, such as age and family income, were controlled. In other words, in order to explore the relations between media use and values, it is important to control relevant variables. Many researchers caution concluding any one-directional causal relation between media use and values because existing value orientations can also affect the use of media, especially when consumption of certain types of media content, such as entertainment, is examined (Sotirovic \& McLeod, 2001). Nonetheless, a substantial body of literature has provided convincing evidence of the impact of media use on values. Therefore, the current study regards media use as a way of absorbing information that may influence cultural values and explores this relation in the WVS 2005 data on China and US.

\section{Research question}

Therefore, based on the proceeding discussion, the current study asks the following:

RQ1: Are there relations between media use and postmaterialist value orientations in China and the US when major demographic variables are controlled?

The demographical variables are age, subjective socioeconomic status, education, and religiosity, which Inglehart and Abramson (1999) found significantly correlated with postmaterialism.

\section{Methods}

\section{Data}

The data used in this study is from the fifth wave of the World Values Study (WVS), WVS 2005, Ballot A. The WVS 2005 split the data set into two parts, Ballot A and 
Ballot B. Ballot A contains results from 48 countries and regions where the complete questionnaire was used. Countries and regions included in Ballot B used a shortened questionnaire. Launched in 1980, the WVS was designed to measure value change in countries around the world over time. It has completed five waves of surveys, and the fifth wave was conducted between 2005 and 2008.

In 2007, the survey was conducted in China using the GPS method to obtain a stratified sample. Interviewers conducted the surveys and 2015 cases were included in the data. The US survey was carried out in 2006 through self-questionnaires using stratified sampling based on census data. The sample size for the US was 1249.

\section{Measurements}

The variables and measures used in the current study are as follows:

\section{Generation group}

The generation groups were defined by regrouping values of V236, year of birth, in the WVS 2005 data. A generation group consisted of 10 years, except when data distribution in the WVS 2005 did not allow clear-cut grouping, in which case a generation group could include more or less than 10 years. Based on data distribution of V236 for China, five generation groups were defined as follows: 1937-1945, 1946-1955, 19561965, 1966-1975, and 1976-1989. A new variable called "China generation groups" was created by regrouping values of V236 to the above groups. By the same token, a new variable called "US generation groups" was created to include seven similar groups: 1915-1925, 1926-1935, 1936-1945, 1946-1955, 1956-1965, 1966-1975, and 19761988 , based on data distribution of V236 for the US. The US data had two more generation groups than the Chinese data because the WVS data included longer life spans of the American respondents than the Chinese respondents.

\section{Postmaterialist values}

Variable Y001 in the WVS 2005, which is the 12-item postmaterialist value index, was used in this study as the measure for postmaterialist value orientations. The values for the 12-item index range from 0 (materialist) to 5 (postmaterialist).

While admitting the difficulty of measuring values directly, Inglehart (1990) maintains that the presence of values could be inferred from people's emphasis on certain types of goals, which is obtained by asking people what they think is the most important goal for a country. Inglehart originally used a four-item index in 1970 (Inglehart, 1990). Later, the index expanded to a 12-item battery, which was also included in the WVS 2005. The 12 items are the following:

1. Maintaining order in the nation

2. Giving people more say in important government decisions

3. Fighting rising prices

4. Protecting freedom of speech

5. A high level of economic growth

6. Making sure that this country has strong defense forces

7. Seeing that people have more say about how things are done at their jobs and in their communities 
8. Trying to make our cities and countryside more beautiful

9. A stable economy

10. The fight against crime

11. Progress toward a less impersonal and more humane society

12. Progress toward a society where ideas count more than money

Items 1, 3, 5, 6, 9, and 10 were designed to assess materialist goals, and the rest were designed to assess postmaterialist goals (Inglehart, 1990). Items 1 through 4 belong to the original and widely adopted four-item index. All items were presented in V69 through V74 in the WVS 2005, which asked people for their first and second choices of things they considered most important (WVS, 2005). The 12-item index was created by summing the responses to 11 items, excluding "try to make our cities and countryside more beautiful" (Davis \& Davenport, 1999). The 12-item index covered a broad range of value orientations, and the researcher considered it more able to capture value shifts in a fast changing society like that of China. Although some scholars have questioned the validity and reliability of the postmaterialism index (Davis \& Davenport, 1999), it remains a useful measurement of human values. The reliability and validity of the postmaterialism index were carefully tested by Inglehart et al. and other scholars (e.g. Inglehart \& Abramson, 1999), and therefore was adopted in the current study.

\section{Traditional media use}

The WVS 2005 measured media sources of information in questions V223 through V229, by asking whether or not the respondents had used different types of sources in the past week, with value 1 indicating use, and value 2 indicting no use. Questions V223 through V227 asked about the use of five traditional media: books, newspapers, television, radio, and magazines. For the purpose of the current study, values for each question from V223 through V227 were recoded as $1 \rightarrow 1,2 \rightarrow 0$, with 1 meaning use and 0 meaning no use. The researcher created an index of traditional media use by summing the recoded values for V223 through V227 and dividing them by 5, obtaining an index with values ranging from 0 (did not use) to 1(used). The KuderRichardson 20 (K-R 20, an equivalent of coefficient alpha for scales consisting of dichotomous items) for the five items was .70, which is acceptable in social science research (Dane, 2011, p. 140).

\section{Internet use}

Question V228 asked about the use of the Internet. The researcher recoded its values as $1 \rightarrow 1,2 \rightarrow 0$, with 1 meaning use and 0 meaning no use. This is a dummy variable.

\section{Broadcast media use}

To test the correlation between use of specific types of media and value orientations, the researcher singled out two types of traditional media, broadcasts, and newspapers, since they are the dominant mass media in China and the US. Values for questions V224 andV226, regarding the use of news and in-depth reports on radio and television were recoded in a new variable called "broadcast media use". 
After recoding V224 and V226 into 1 (used) and 0 (did not use), the researcher added these two values and then divided the sum by 2 , thus obtained the score for broadcast media use, with values of 0 (no broadcast), 0.5 (either news or in-depth), and 1 (both news and in-depth on broadcast media). Although the K-R $20(=.61)$ for this variable was not as high as expected, its validity was not unacceptable.

\section{Newspaper use}

Another dummy variable was created by recoding V223, newspaper use, into 1 (used) and 0 (did not use).

There were also a few control variables, all equally weighted in the current study:

Age

This variable used the values of V237 in the WVS 2005, the actual age of respondent.

\section{Education}

This variable used the values of V238, measured by the highest education level achieved, ranging from 1 (no formal education) to 9 (university-level education with degree). Abramson and Inglehart (1994) believed that education, as a complex variable, actually tapped a number of other variables, such as parental status during respondents' formative years and respondents' information and skill levels. Hence, controlling education partially controls variations incurred by those variables.

\section{Social class}

V252 in the WVS 2005 measured the subjective evaluation of one's own social class, ranging from 1 (upper class) to 5 (lower class). The values were reversely recoded in the current study so that a higher value represented higher social class: $5=$ upper class, $4=$ upper middle class, $3=$ lower middle class, $2=$ working class, and $1=$ lower class.

\section{Religiosity}

In the WVS 2005, V9 measured how important religion was in the respondent's life, with $1=$ very important, $2=$ rather important, $3=$ not very important, and $4=$ not at all important. V187 provided three alternatives for respondents to identify themselves: $1=$ a religious person, $2=$ not a religious person, and $3=$ a convinced atheist. V192 asked respondents to mark how important God was in their lives on a 10 -point scale, with $1=$ not at all and $10=$ very important. After V9 and V187 were reversely recoded, the alpha of the $z$ scores of those three variables was .87 . The sum of the $\mathrm{z}$ scores was used as the value of religiosity.

Distributions of all the variables, except the two dummy variables, were not significantly deviated from normality because the absolute value of their skewness and kurtosis was less than 1.96 (Field, 2009, p. 139), thus meeting the assumption of using ordinary least squares (OLS) regression. Moreover, several studies on postmaterialism used OLS regression to analyze data, and their analysis normally contained dummy 
variables (e.g., Franzen \& Meyer, 2009; Goksen, Adaman, \& Zenginobuz, 2002; Inglehart \& Abramson, 1994, 1999; Yao, 2008). The current study also used OLS regression and ANOVA to analyze the data.

\section{Results}

One-way ANOVA was performed to test H1: younger generations have stronger postmaterialist value orientations than older generations in China. There are five generation groups in the data on China from the 1930s to the late 1980s. The mean of the 12-item postmaterialist index for the oldest generation group is 1.06, and 1.64 for the youngest generation group. The youngest generation group has stronger postmaterialist values than the oldest one. Meanwhile, among the five generation groups, as the generation groups became younger, the mean of the 12-item postmaterialist index increased steadily (see Table 1). The overall between-groups difference is statistically significant, $\mathrm{F}(4)=11.323, \mathrm{p}<0.001$. Meanwhile, a post hoc test shows that the mean differences between the youngest generation group and each of the four older generation groups are all statistically significant (see Table 2). The youngest generation group has a higher mean than each older generation group. The older a generation group is, the bigger the difference in the postmaterialist index mean between it and the youngest generation group. The mean difference between the youngest generation group (1976-1989) and the oldest one (1937-1945) is .578 $(\mathrm{p}<0.01)$, and the mean difference between the youngest generation group and the second youngest one $(1966-1975)$ is $.321(\mathrm{p}<0.01)$ (see Table 2).

Overall, the younger generations in China have stronger postmaterialist values than older generations, and this difference is statistically significant. Therefore, H1 was fully supported.

Table 1. Postmaterialist values: Chinese and US generation groups.

\begin{tabular}{lccc}
\hline Generation groups & Sample size & Mean & Standard deviation \\
\hline & China & & \\
$1937-1945$ & 140 & 1.06 & 1.107 \\
$1946-1955$ & 271 & 1.13 & .954 \\
$1956-1965$ & 324 & 1.22 & 1.090 \\
$1966-1975$ & 364 & 1.32 & 1.120 \\
$1976-1989$ & 299 & 1.64 & 1.136 \\
Total & 1398 & 1.30 & 1.101 \\
& US & & \\
$1915-1925$ & 35 & 1.86 & 1.141 \\
$1926-1935$ & 109 & 1.92 & 1.219 \\
$1936-1945$ & 156 & 1.83 & 1.287 \\
$1946-1955$ & 242 & 1.99 & 1.236 \\
$1956-1965$ & 232 & 2.03 & 1.303 \\
$1966-1975$ & 212 & 2.11 & 1.268 \\
$1976-1988$ & 224 & 2.03 & 1.255 \\
Total & 1210 & 1.99 & \\
\hline
\end{tabular}


Table 2. Post hoc test of generational differences of values in China.

\begin{tabular}{lccc}
\hline Generation group I & Generation group II & Mean difference (I-II) & Standard error \\
\hline $1976-1989$ & $1937-1945$ & $.578^{*}$ & .111 \\
$1946-1955$ & $.517^{*}$ & .091 \\
$1956-1965$ & $.423^{*}$ & .087 \\
$1966-1975$ & $.321^{*}$ & .085 \\
\hline
\end{tabular}

$* p<0.01$

An independent samples T-test was performed to test $\mathrm{H} 2$, which states that American society has stronger postmaterialist value orientations than Chinese society as a whole. The postmaterialist index means are 1.99 for the US and 1.3 for China in the WVS 2005 (see Table 1). The difference between these mean values is statistically significant at $\mathrm{t}(2606)=14.995, \mathrm{p}<.001$. In other words, the US population has stronger postmaterialist value orientations than the Chinese population. Therefore, H2 was fully supported.

The generational differences in the postmaterialist index mean in China were already known. To test H3, A one-way ANOVA was conducted on the same variable for the US data in order to compare the significance in differences of postmaterialist index means among generations in China and the US.

In the WVS 2005 data, the postmaterialist index mean for the youngest generation in the US in the data from 1976 to 1988 is 2.03 , and for the oldest generation in the data from 1915 to $1925,1.86$. As in China, the younger generation groups generally show a higher postmaterialist index mean than the older groups in the US (see Table 1). However, the mean difference between the youngest generation group and the oldest group is 0.17 , which is much smaller than the difference in China (.578), and the difference is not statistically significant at $F(6)=.958, p>.05$. In other words, compared with China, the generational differences in postmaterialist values in the US are less obvious and significant. Therefore, H3 was also supported.

To answer RQ1, which asks whether there are any relations between media use and postmaterialist values in China and the US, regression was conducted. Media use variables were used as independent variables, controlling for age, education, social class, and religiosity. These four demographic variables were used as the first block of independent variables in the regression models.

In both China and the US, the use of traditional media, which includes television, newspapers, radio, books and magazines, seems to have an impact on postmaterialist values (In the US, $\beta=.07, \mathrm{p}<.05$; in China, $\beta=.07, \mathrm{p}=.06$.) Normally, researchers take $\mathrm{p}<.05$ as a critical value to evaluate statistical significance. Some studies also use the significant levels of .10 and even .15 (Iyengar \& Kinder, 2010). Compared with traditional media use, Internet use seems to have a weak impact on values in China $(\beta=.06, p=.10)$ and no impact in the US (see Table 3 ). The situation is similar when Internet use is compared with the use of newspapers and broadcast media. Use of the Internet and newspapers has weak relations to postmaterialist values in China (for Internet, $\beta=.06, p=.10$; for newspapers, $\beta=.08, p<.05$ ), but no such relations in the US (see Table 4). Broadcast media use has no relationship with postmaterialism in either the US or China. 
Table 3. Regression of postmaterialism on traditional media and internet use and demographical variables.

\begin{tabular}{lcc}
\hline & \multicolumn{1}{c}{ China } & $\mathrm{US}$ \\
\hline Age & $-0.009^{* *}(0.003,-.11)$ & $-0.004^{\mathrm{a}}(0.002,-.05)$ \\
Education & $0.06^{* * *}(0.02, .12)$ & $0.13^{* * *}(0.03, .13)$ \\
Social class & $0.02(0.04, .01)$ & $-0.04(0.04,-.03)$ \\
Religiosity & $0.05^{* * *}(0.02,0.11)$ & $-0.08 * * *(0.02,-.15)$ \\
Traditional media use & $0.26^{\mathrm{b}}(0.14, .07)$ & $0.32^{*}(0.15, .07)$ \\
Internet use & $0.17^{\mathrm{c}}(0.11, .06)$ & $-0.11(0.09,-.04)$ \\
& $\mathrm{R}^{2}=.08$ & $\mathrm{R}^{2}=.05$ \\
\hline
\end{tabular}

Note: Values shown in this table represent B. Values included in the parentheses represent SE B (first number) and $\beta$ (second number). *p<0.05;**p $\leq 0.01 ; * * * p \leq 0.001 ;{ }^{\mathrm{a}} p=.14$; ${ }^{\mathrm{b}} p=.06 ;{ }^{\mathrm{c}} p=.10$.

Judging from $\beta$ values within individual models for China and the US, use of traditional media has stronger predicting power for postmaterialist values than use of the Internet (see Table 3). While the use of newspapers and the Internet does not demonstrate an impact on postmaterialist values in the US data, it shows a weak impact in the China data.

\section{Discussion}

The generational differences in value orientations in China shown in this study provide strong support for Inglehart's theory of value change as a result of improving living conditions in the formative years.

As the results showed, generations born after the Cultural Revolution (19761989) demonstrate much stronger postmaterialist values than previous generations, which could be explained as a result of the greatly improved living conditions in most households after China implemented economic reform and opening-up policies in 1978 (Harding, 1987; Hutchings, 2001). Since then, China's economic development

Table 4. Regression of postmaterialism on Internet, newspapers, and broadcast media use and demographic variables.

\begin{tabular}{lcc}
\hline & \multicolumn{1}{c}{ China } & $\mathrm{US}$ \\
\hline Age & $-0.01 * *(0.003,-.10)$ & $-0.002(0.002,-.03)$ \\
Education & $0.06^{* * *}(0.02, .13)$ & $0.14 * * *(0.03, .14)$ \\
Social Class & $0.02(0.04, .02)$ & $-0.04(0.04,-.03)$ \\
Religiosity & $0.05^{* * *}(0.02, .11)$ & $-0.08 * * *(0.02,-.14)$ \\
Internet use & $0.17^{\mathrm{a}}(0.11, .06)$ & $-0.04(0.09,-.02)$ \\
Newspaper use & $0.19 *(0.09, .08)$ & $0.02(0.09, .006)$ \\
Broadcast media use & $-0.09(0.10,-.03)$ & $-0.04(0.13,-.01)$ \\
& $\mathrm{R}^{2}=.08$ & $\mathrm{R}^{2}=.04$ \\
\hline
\end{tabular}

Note: Values shown in this table represent $B$. Values included in the parentheses represent $S E B$ (first number) and $\beta$ (second number). $* p<0.05 ; * * p \leq 0.01 ; * * p \leq 0.001 ;{ }^{\mathrm{a}} p=.10$. 
has been astonishing, jumping from a poor agricultural economy to the world's second largest economy in just three decades. For Chinese people, living standards were significantly higher after the opening-up and reform than before. The difference was between a central-planned and a market economy, consumer goods scarcity and surplus, buying limited food with government-issued vouchers and consuming electronic appliances with cash, having no money beyond basic survival needs and spending on luxury goods, entertainment and vacations, and so on. These changes happened in a short period of time. In contrast, the change from a pre-industrial to an industrial society in the US took much longer at a more gradual pace. This difference in the two countries' modernization processes could explain the greater generational differences of value orientations in China than in the US.

On the other hand, in the World Values Survey, the US population as a whole demonstrates stronger postmaterialist values than does its counterpart in China. It is fair to say that US society is still more postmaterialist in terms of value orientations than China. However, on average, different generations in the US do not differ as much from each other in postmaterialist values as they do in China.

The results also show that media, especially traditional media, play some role in cultivating postmaterialist values, particularly in China. The regression models show that in China, people who use traditional media more are more likely to have postmaterialist values, and according to the standardized regression coefficients, such a relation is a bit stronger than with people who use the Internet more. The situation is similar when the uses of newspapers and the Internet are compared (see Tables 3 and 4).

Among the 11 items used in the World Values Survey's postmaterialist value index (Davis \& Davenport, 1999), five concern the following postmaterialist values: (1) giving people more say in important government decisions; (2) protecting freedom of speech; (3) seeing that people have more say about how things are done at their jobs and in their communities; (4) progress toward a less impersonal and more humane society; and (5) progress toward a society where ideas count more than money. It might seem bizarre that the use of traditional media in China would contribute to developing those values, but it might just be the case. Traditional media in China, including broadcast and print media, are controlled largely by the state and under the scrutiny of party propaganda authorities. Despite the recent trend to diversification in media content, especially entertainment programming (e.g., Zhao, 1998), much media content, including news, still carries messages from the communist party. From Deng Xiaoping's "two civilizations" (material and spiritual), Jiang Zeming's "three representatives" (representing advanced culture, advanced productive forces, and interests of the people), to Hu Jintao's "harmonious society", the party has always strived, according to what it tells the public through the media, to lead the country to become highly developed, achieving economic prosperity and beyond. The party has always claimed that the people are the true masters of the country, and it has promised many rights, including political rights, to the people. The party also has always stressed the moral message that money should not be the sole goal of people's pursuits, and it has encouraged altruism (Chu \& Hsu, 1979). Under Hu Jintao's "harmonious society" initiative, putting people first has become a principle stressed across Chinese society (Guo \& Guo, 2008). What has happened in reality notwithstanding, the party is very careful about its public representation through the mass media. It therefore is not surprising that the use of traditional media in China has some impact on cultivating the postmaterialist values listed above. In fact, Zhu and He (2002) hypothesized that 
using traditional media in China would decrease postmaterialism, but they found little evidence to support that hypothesis. Other scholars pointed out that traditional media, particularly newspapers, contain more news than entertainment and are more effective in bolstering postmaterialist values, such as environmental concerns (Yao, 2008) and political knowledge (Hollander, 2005).

The relations between media use and postmaterialist values are not as obvious in the US results, in which education and social class are much stronger predictors for postmaterialist values than media use (see Tables 3 and 4). The media system in the US and people's attitudes toward the media are very different from those in China. It could be that the US has already passed the stage where media consumption has a strong effect on people's postmaterialist values. It could also be that people with postmaterialist values in the US do not pay much attention to the media.

A limitation of the current study should be pointed out. Since the WVS is designed to capture general trends in value changes across the world, it is useful to describe changes at a macro level, but not to provide precise empirical evidence for relations among more specific values and types of media use. For example, by using dichotomy measurement, the WVS data only indicate whether people use certain type of media or not, leaving out information such as the amount of time spent using different types of media and the specific content consumed. A more specific research design is required to explore the relations between values and media use at a micro level.

The results show that in both China and the US, some demographical variables, namely, age, education, and religiosity, have statistically significant power to predict postmaterialism (see Tables 3 and 4). Younger generations prefer postmaterialism more than older generations. In addition, more education increases the acceptance of postmaterialism, and this trend is approximately the same in the two societies. Religiosity shows some interesting results. In the US, religiosity decreases postmaterialist values, as Inglehart and Abramson (1999) discussed, but in China, it increases postmaterialist values. The reason that people in China who have stronger religious beliefs tend to be more postmaterialist in value orientations is unclear. An intriguing area for future research is to explore the reasons that religiosity has opposite effects on postmaterialist values in China and the US.

Although it is clear that some demographic variables can explain postmaterialist value orientations in both China and the US, and media use can explain these orientations at a lower confidence level, it should be noted that the reasons that people subscribe to postmaterialist values need further exploration. The coefficient of determination, which shows how much variations in postmaterialist values are explained, is low in the models used by both the current study and Inglehart and Abramson (1999). Future research might determine important variables that have been ignored thus far.

\section{Acknowledgements}

The author wishes to thank Prof. Wenfang Tang and Dr Qingjiang Yao for their valuable contributions to this paper.

\section{Note}

1. Retrieved from http://www.worldvaluessurvey.org/ 


\section{Notes on contributor}

Zhaoxi Josie Liu is a PhD candidate in the School of Journalism and Mass Communication at the University of Iowa, expecting to receive her doctorate in December 2012. Her research focuses on transformations in journalism and mass media in China in recent decades. Her work has appeared in American Journal of Media Psychology and Journal of Media and Religion.

\section{References}

Abramson, P.R., \& Inglehart, R. (1994). Education, security, and postmaterialism: A comment on Duch and Taylor's "postmaterialism and the economic condition". American Journal of Political Science, 38, 797-824.

Ball-Rokeach, S., Rokeach, M., \& Grube, J.W. (1984). The great American values test: Influencing behavior and belief through television. New York: Free Press.

Besley, J. (2008, May). Television exposure and core values, Paper presented at the Annual Convention of the International Communication Association, Montreal, Canada

Brady, A. (2008). Marketing dictatorship: Propaganda and thought work in contemporary China. Lanham, MD: Rowman \& Littlefield.

Carlson, J.M. (1993). Television viewing: Cultivating perceptions of affluence and support for capitalist values. Political Communication, 10(3), 243-257.

Cheng, H., \& Schweitzer, J.C. (1996). Cultural values reflected in Chinese and US television commercials. Journal of Advertising Research, 36(3), 27-45.

Chu, G.C., \& Hsu, F.L. K. (Eds.). (1979). Moving a mountain: Communication \& cultural change in China. Honolulu: University of Hawaii Press.

Dane, F.C. (2011). Evaluating research: Methodology for people who need to read research. Thousand Oaks, CA: Sage.

Davis, D.W., \& Davenport, C. (1999). Assessing the validity of the postmaterialism index. The American Political Science Review, 93(3), 649-664.

Field, A. (2009). Discovering statistics using SPSS (3rd ed.). Thousand Oaks, CA: Sage.

Franzen, A., \& Meyer, R. (2010). Environmental attitudes in cross-national perspective: A multilevel analysis of the ISSP 1993 and 2000. European Sociological Review, 26(2), 219-234.

Goksen, F., Adaman, F., \& Zenginobuz, E.U. (2002). On environmental concern, willingness to pay, and postmaterialist values: Evidence from Istanbul. Environment and Behavior, 34 (5), 616-633.

Guo, B., \& Guo, S. (2008). China in search of a harmonious society. In S. Guo (Ed.), China in search of a harmonious society (pp. 1-12). Plymouth, UK: Lexington Books.

Harding, H. (1987). China's second revolution: Reform after Mao. Washington, DC: Brookings Institution.

Harmon, M.D. (2001). Affluenza: Television use and cultivation of materialism. Mass Communication \& Society, 4(4), 405-418.

Hollander, B.A. (2005). Late-night learning: Do entertainment programs increase political campaign knowledge for young viewers? Journal of Broadcasting and Electronic Media, $49,402-415$.

Hutchings, G. (2001). Modern China: A guide to a century of change. Cambridge, MA: Harvard University Press.

Inglehart, R. (1981). Post-materialism in an environment of insecurity. The American Political Science Review, 75(4), 880-900.

Inglehart, R. (1990). Culture shift in advanced industrial society. Princeton, NJ: Princeton University Press.

Inglehart, R. (1997). Modernization and postmodernization: Cultural, economic, and political change in 43 societies. Princeton, NJ: Princeton University Press.

Inglehart, R. (2000). Globalization and postmodern values. Washington Quarterly, 23(1), $215-228$ 
Inglehart, R. (2008). Postmaterialist values and the shift from survival to self-expression values. In R. Dalton \& H. Klingemann (Eds.), The Oxford handbook of political science (pp. 223-239). New York: Cambridge University Press.

Inglehart, R., \& Abramson, P.R. (1994). Economic security and value change. The American Political Review, 88(2), 336-354.

Inglehart, R., \& Abramson, P.R. (1999). Measuring postmaterialism. The American Political Review, 93(3), 665-677.

Inglehart, R., Basáñez, M., \& Menéndez Moreno, A. (1998). Human values and beliefs: A crosscultural sourcebook. Ann Arbor: University of Michigan Press.

Iyengar, S., \& Kinder, D.R. (2010). News that matters: Television and American opinion. Chicago, IL: The University of Chicago Press (updated ed).

Lee, C.C. (2003). The global and national of the Chinese media: Discourses, markets, technology, and ideology. In C.C. Lee (Ed.), Chinese media, global contexts (pp. 1-31). London: Routledge.

Liu, A.P. L. (1971). Communications and national integration in communist China. Ann Arbor: University of Michigan Press.

Lull, J. (1991). China turned on: Television, reform and resistance. New York: Routledge.

Lynch, D.C. (1999). After the propaganda state: Media, politics, and "thought work" in reformed China. Palo Alto, CA: Stanford University Press.

Reimer, B., \& Rosengren, K.E. (1990). Cultivated viewers and readers: A life-style perspective. In N. Signorielli \& M. Morgan (Eds.), Cultivation analysis: New directions in media effects research (pp. 181-205). Newbury Park: Sage.

Rokeach, M. (1973). The nature of human values. New York: Free Press.

Schurman, F. (1968). Ideology and organization in communist China. Berkeley: University of California Press.

Schwartz, S.H. (1994). Are there universal aspects in the structure and contents of human values? Journal of Social Issues, 50(4), 19-45.

Sotirovic, M., \& McLeod, J.M. (2001). Values, communication behavior, and political participation. Political Communication, 18(3), 273-300.

Tai, Z. (2006). The Internet in China: Cyberspace and civil society. New York: Routledge.

Tang, W. (2000). Chinese urban life under reform: The social contract. New York: Cambridge University Press.

Tang, W. (2005). Public opinion and political change in China. Palo Alto, CA: Stanford University Press.

Welzel, C. (2008). Individual modernity. In R. Dalton \& H. Klingemann (Eds.), The Oxford handbook of political science (pp. 185-205). New York: Cambridge University Press.

Yang, Q., \& Tang, W. (2010). Exploring the sources of institutional trust in China: Culture, mobilization, or performance? Asian Politics and Policy, 2(3), 415-436.

Yao, Q. (2008). Media use, postmaterialist values, and political interest: The making of Chinese environmentalists and their views on their social environment. Asian Journal of Communication, 18(3), 264-279.

$\mathrm{Yu}, \mathrm{H}$. (2009). Media and cultural transformation in China. New York: Routledge.

Zha, J. (1995). China pop: How soap operas, tabloids, and bestsellers are transforming a culture. New York: New Press.

Zhao, Y. (1998). Media, market, and democracy in China: Between the party line and the bottom line. Urbana, IL: University of Illinois Press.

Zhao, Y. (2008). Communication in China: Political economy, power, and conflict. Lanham, MD: Rowman \& Littlefield.

Zhang, Y., \& Harwood, J. (2002). Television viewing and perception of traditional Chinese values among Chinese college students. Journal of Broadcasting and Electronic Media, 46 (2), 245-264. 
Zheng, Y. (2007). Technological empowerment: The Internet, state, and society in China. Palo Alto: Stanford University Press.

Zhou, Y. (2005). Historicizing online politics: Telegraphy, the Internet, and political participation in China. Palo Alto: Stanford University Press.

Zhu, J., \& He, Z. (2002). Information accessibility, user sophistication, and source credibility: The impact of the Internet on value orientations in Mainland China. Journal of Computer-Mediated Communication, 7(2) doi: 10.1111/j.1083-6101.2002.tb00138.x. 
